\title{
Influence of preheating temperature on hardness and microstructure of PBF steel hs6-5-3-8
}

\author{
Saewe, Jasmin1; Wilms, Markus Benjamin1; Jauer, Lucas1; Schleifenbaum, Johannes Henrich1 \\ ${ }^{1}$ Fraunhofer Institute for Laser Technology (ILT), Germany
}

\begin{abstract}
Laser powder bed fusion (LPBF) is an additive manufacturing process employed in many industries, for example for aerospace, automotive and medical applications. In these sectors, mainly nickel-, aluminum- and titanium-based alloys are used. In contrast, the mechanical engineering industry is interested in more wear-resistant steel alloys with higher hardness, both of which can be achieved with a higher carbon content, like in high-speed steels. Since these steels are susceptible to cracking, preheating needs to be applied during processing by LPBF. In a previous study, we applied a base plate preheating temperature of $500{ }^{\circ} \mathrm{C}$ for HS6-5-3-8 with $1.3 \%$ carbon content. We were able to manufacture dense ( $>$ >99.9 \%) and crack-free parts from HS6-5-3-8 with a hardness > 62 HRC (as built) by LPBF. In this study, we investigate the influence of preheating temperatures up to $600{ }^{\circ} \mathrm{C}$ on hardness and microstructure dependent on part height for HS6-5-3-8. The microstructure was studied by light optical microscopy (LOM), scanning electron microscopy (SEM) and electron backscatter diffraction (EBSD). The analysis of hardness and microstructure at different part heights is necessary because state-of-the-art preheating systems induce heat only into the base plate. Consequently, parts are subjected to temperature gradients and different heat treatment effects depending on part height during the LPBF process.
\end{abstract}

\section{Keywords}

LPBF, Laser Powder Bed Fusion, SLM, Selective Laser Melting, High-speed steel, tool steel, high carbon content, preheating temperature

\section{Introduction and State of the Art}

The Additive Manufacturing (AM) process Laser Powder Bed Fusion (LPBF), also known as Selective Laser Melting (SLM), is used in multiple industries such as aerospace, automotive and medical application [1,2]. Metal powder is melted layer by layer in the LPBF process with a focused laser beam that melts selected areas to fuse the material into a 3D part [3]. The multiple advantages of this process are also interesting for roller bearings where a flexible design of cooling channels, adapted to any type of application, can be achieved with LPBF. Moreover, LPBF makes it possible to easily adapt the complete design which makes it also very interesting for rapid prototyping and manufacturing.

Most steels commonly used with LPBF have insufficient wear resistance and, therefore, cannot be used in the production of roller bearings as they would not resist the loads. Bearing steels are special tool steels, have often similar properties as high-speed steels and are suitable for the operating conditions to which a roller bearing is subjected. But these steels are considered as hardly weldable because of their high carbon content (>0.4 wt.-\%). 
In research, LPBF of some steels with a higher carbon content (>0.6 wt.-\%) has been investigated. The high-speed steel AISI M2 (1.3323) with 0.9 wt.- $\%$ carbon is investigated in various studies. Liu et al. published a primary study on processing of M2 [4]. Simple parts can be manufactured crack-free and with a part density of $97 \%$ by using a base plate preheating temperature (BPPT) of $180{ }^{\circ} \mathrm{C}$. Without preheating, cracks are formed perpendicular to the mounting direction and the components are detached from the base plate. In a second investigation, fine carbide and dendrite networks can be classified [5]. Kempen et al. [6] investigated the influence of preheating temperatures during LPBF on part density of M2. With a BPPT of $200{ }^{\circ} \mathrm{C}$, crack-free parts with part densities of $99.8 \%$ are achieved. The principle of remelting each layer is also investigated which leads to higher martensite content and to more brittle material. Zumhofen et al. [7] process M2 using BPPT of $160-400{ }^{\circ} \mathrm{C}$ to manufacture parts with densities of $99 \%$. By manufacturing Cantilevers at different BPPTs, the residual stresses and distortions were demonstrated. With increasing BPPT the stresses decreased. Feuerhahn et al. [8] manufacture the tool steel X110CrMoV18-2 with 1.04 wt.- $\%$ carbon by means of LPBF. The parts were crack-free without applying preheating temperatures. For subsequent use in "micro tooling", the focus of the investigation is the hardness increase of LPBF parts by post process heat treatment. The hardness can be increased from 44.9 HRC to 63 HRC by post heat treatments. Sander [9] investigates the processing of casting alloy Fe85Cr4Mo8V2C1 with LPBF. A parameter development for the processing is carried out and the influence of the in-situ heat treatment on the microstructure is investigated. In addition, the alloy is adjusted to Fe90.8Cr4V0.5W4C0.7. Due to the new alloy composition, components can be manufactured crack-free without using preheating. In previous studies the roller bearing material M50 with 0.8 wt.-\% carbon content [10, 11 12] and the high-speed steel HS6-5-3-8 [13] were investigated. In conclusion, the use of a base plate preheating system is a promising approach for reducing the temperature gradient and internal stresses and therefore reduce cracking tendencies of parts.

This paper focuses on the high-speed steel HS6-5-3-8, also known as 1.3294 or ASP®2030, with 1.3 wt.-\% carbon content. We investigate the influence of BPPTs of $200{ }^{\circ} \mathrm{C}$ up to $600{ }^{\circ} \mathrm{C}$ during LPBF on the microstructure and hardness as a function of part height.

\section{Material and Methods}

For this study the high-speed steel HS6-5-3-8 (1.3294) was used. HS6-5-3-8 is a cobalt containing high speed-steel for high performance cutting and cold work tools. Exemplary applications are drills, end mills, shaper cutters and hobs. The chemical composition of the powder as specified by the manufacturer Deutsche Edelstahlwerke GmbH (DEW) is shown in Table 1. The particle size of HS6-5-3-8 powder is $20-53 \mu \mathrm{m}$ and evaluated by sieve analysis of DEW.

Table 1: Chemical Composition of HS6-5-3-8 (by DEW)

\begin{tabular}{|c|c|c|c|c|c|c|c|c|c|}
\hline Chemical Elements[wt.-\%] & $\mathrm{C}$ & $\mathrm{Si}$ & $\mathrm{Mn}$ & $\mathrm{Cr}$ & $\mathrm{Mo}$ & $\mathrm{Co}$ & $\mathrm{W}$ & $\mathrm{V}$ & $\mathrm{Fe}$ \\
\hline HS6-5-3-8(1.3294, ASP2030) & 1.33 & 0.5 & 0.3 & 4.1 & 4.6 & 8.3 & 6.3 & 3.0 & Balance \\
\hline
\end{tabular}

For the experiments, a modified laboratory scale LPBF machine (Aconity MIDI) from Aconity3D GmbH, Germany was used. The machine is equipped with a fiber laser from IPG Laser $\mathrm{GmbH}$, Germany with a wavelength of $1070 \mathrm{~nm}$, a maximum output power of $400 \mathrm{~W}$ and a 3D scan system from Scanlab GmbH, Germany (varioSCAN40 and intelliSCAN20). The laser 
spot has a Gaussian shape with $80 \mu \mathrm{m}$ diameter (1/e2) in the focal plane. The resistive preheating system of the machine can heat the base plate up to $800^{\circ} \mathrm{C}$.

The experiments were carried out under an argon inert-gas atmosphere. The oxygen content was less than 200 ppm when starting the preheating ramp and maximum $100 \mathrm{ppm}$ when starting the experiments. The atmosphere in the machine had approx. 50 mbar overpressure compared to the ambient atmosphere. The layer thickness of $30 \mu \mathrm{m}$ was kept constant for all samples prepared within this study. The experiments were carried out with four different BPPTs $\mathrm{T}_{\mathrm{H}, 1}=200{ }^{\circ} \mathrm{C}, \mathrm{T}_{\mathrm{H}, 2}=350{ }^{\circ} \mathrm{C}, \mathrm{T}_{\mathrm{H}, 3}=500{ }^{\circ} \mathrm{C}$ and $\mathrm{T}_{\mathrm{H}, 4}=600{ }^{\circ} \mathrm{C}$. The heating ramp was programmed to heat up and to cool down with a fixed rate of $10 \mathrm{~K} / \mathrm{min}$ after the build job. In terms of process parameters, 15 test specimens were built with varying laser power of 130, 200 or $260 \mathrm{~W}$ and hatch distance of 80 or $100 \mu \mathrm{m}$. The volume energy density was adjusted between 70 to $100 \mathrm{~J} / \mathrm{mm}^{3}$ by varying the scan speed. The test specimens were randomly placed over the base plate. This paper focusses on specimen no. 2 which is built using a laser power of $200 \mathrm{~W}$, a hatch distance of $100 \mu \mathrm{m}$ and a scan speed of $670 \mathrm{~mm} / \mathrm{s}$ resulting in a volume energy density of $100 \mathrm{~J} / \mathrm{mm}^{3}$. The specimen was chosen because of part density over $99.9 \%$ and no visible conspicuousness during the LPBF process or on the surface of the specimen. A zig-zag pattern with an alternating hatch rotation of 90 degrees per layer was used as exposure strategy for building the specimens. Test specimens with a dimension of $10 \times 10 \times 10 \mathrm{~mm}^{3}$ were manufactured for part density, hardness and microstructure evaluation.

All specimens were cut from the base plate by electrical discharge machining (EDM) wire cutting. The specimens were then cut in the middle by cutting machine, embedded and polished. To visualize the microstructure of the test specimens, they were etched with Kalling I $\left(\mathrm{HCl}, \mathrm{CuCl}_{2}\right)$ at room temperature for $1-2 \mathrm{~s}$. The polished and etched cross-sections were analyzed by light optical microscopy (LOM). The hardness was measured with HV10 according to DIN EN ISO 6507 with minimum of 16 points. SEM images were captured using a field emission scanning electron microscope (FE-SEM) Zeiss ULTRA 55 (Carl Zeiss Microscopy GmbH, Germany) equipped with an Oxford TETRA detector (Oxford Instruments plc, UK). EBSD measurements were carried out with a Zeiss XBeam 1540 with Nordlys camera and a step-size of $0.12 \mu \mathrm{m}^{2}$ with subsequent data analysis software Aztec by Oxford. The retained austenite (RA) measurements were realized by Zeiss LEO 1550 with a step-size of $0.176 \mu \mathrm{m}^{2}$.

\section{Results and Discussion}

Fig. 1a shows a schematic sketch of the specimen arrangement on the base plate. The numbers also represent the order of irradiation exposure. Furthermore, the directions of powder application and inert gas flow are marked. After completion of the last exposure in the experiments, a final layer of powder is applied. Fig. $1 \mathrm{~b}$ shows the images of the powder bed at preheating temperatures $\mathrm{T}_{\mathrm{H}, 1}=200{ }^{\circ} \mathrm{C}, \mathrm{T}_{\mathrm{H}, 2}=350{ }^{\circ} \mathrm{C}, \mathrm{T}_{\mathrm{H}, 3}=500{ }^{\circ} \mathrm{C}$ and $\mathrm{T}_{\mathrm{H}, 4}=600{ }^{\circ} \mathrm{C}$ after the cooling stage has been completed. Already during the cooling stage, occasionally blow-ups can be detected on the powder bed. The cross-section of the specimens causing blow-ups show different crack morphologies in Fig. 1b.

For the experiment with $\mathrm{T}_{\mathrm{H}, 1}$, in case of samples causing a blow-up, cracks on the surface of the sample can be visually detected after removal of the powder. In the cross-section of these specimens, the crack gap has a curved course over the cross section surface. The cracks are mostly oriented perpendicular to the build direction $\mathrm{z}$.

During the cooling stage of the experiment with $\mathrm{T}_{\mathrm{H}, 2}$ the powder bed is disrupted by a blow-up of only one specimen (no. 15). Further blow-ups do not occur during this experiment. Nevertheless, fine cracks not leading to visible blow-ups and therefore possibly caused by metallurgical preparation are detected in almost all cross-sections of the samples. 
The powder bed after the experiment with $\mathrm{T}_{\mathrm{H}, 3}$ shows blow-ups for all specimens and is marked by deep furrows between the samples. The cracks on the side surfaces of the samples become visible as soon as the samples are removed from the process chamber. The cracks are also observed in the cross sections of all specimens.

The experiment with $\mathrm{T}_{\mathrm{H}, 4}$ deviates from the previous observations. No blow-ups of the samples in the powder bed are observed until the end of the cooling stage, indicating substantial reduction of internal stresses during manufacturing. However, after removal from the process chamber, cracks on the side surfaces of all samples become visible. In many cases, several cracks are detected per side surface. The frequency and short length of the cracks lead to the hypothesis that the cracks appear in stages during irradiation exposure. The residual stresses built up in the specimens thus lead to cracks after several dozen layers already during exposure, despite preheating.
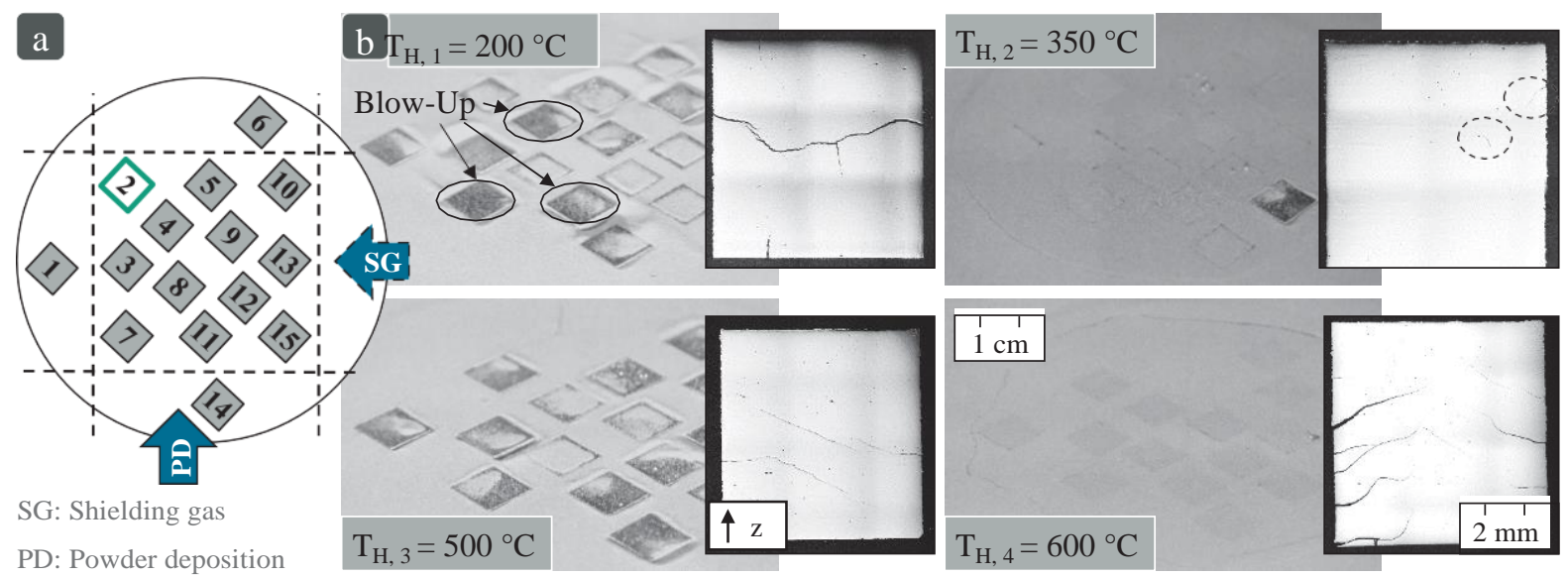

Fig. 1: Schematic sketch of specimen order on base plate (a), final powder layer with blow-ups after the cooling stage and cross-section of exemplary specimen with cracks, built at $\mathrm{T}_{\mathrm{H}, 1}, \mathrm{~T}_{\mathrm{H}, 2}$ $\mathrm{T}_{\mathrm{H}, 3}$ and $\mathrm{T}_{\mathrm{H}, 4}(\mathrm{~b})$.

These blow-ups of the powder bed are believed to occur by the unloading of the thermally induced inherent stresses in the samples. The microstructure can transform during the cooling stage and the residual stresses in the specimens are assumed to become too high during a phase change and the resulting contraction of the volume. A crack in the specimen spreads at suitable defects or weak points. The impulse resulting from this crack is transferred to the powder bed resulting is ejection of powder material from the surface. Apparently the impulse and the visibility of the contour are sufficient as a first indication for the formation of cracks due to the discharge of the residual stress in the specimens. After removal from the process chamber, in case of samples causing a blow-up, the cracks on the surface of the sample always can be detected visually.

Fig. 2 shows LOM images of etched cross sections of specimens 2 built at different preheating temperatures $\mathrm{T}_{\mathrm{H}, 1}=200{ }^{\circ} \mathrm{C}, \mathrm{T}_{\mathrm{H}, 2}=350{ }^{\circ} \mathrm{C}, \mathrm{T}_{\mathrm{H}, 3}=500{ }^{\circ} \mathrm{C}$ and $\mathrm{T}_{\mathrm{H}, 4}=600{ }^{\circ} \mathrm{C}$. The image is taken in the upper right quadrant of the cross-section. By etching the cross sections, the microstructure and melt track boundaries are revealed. The melt pool boundaries are marked with dashed lines.

At $\mathrm{T}_{\mathrm{H}, 1}, \mathrm{~T}_{\mathrm{H}, 2}$ and $\mathrm{T}_{\mathrm{H}, 3}$ long needle-shaped lancets are observed within the grain boundaries. The dendritic structure is marked in the image of $\mathrm{T}_{\mathrm{H}, 1}$. In the area of the melt pool boundary, cellular structures are increasingly observed. Columnar dendritic structures are visible that grow over several layers. This is an indication of epitaxial grain growth during the process, where grains grow in the direction of the thermal gradient through the melt pool boundaries. At $\mathrm{T}_{\mathrm{H}, 3}$ in Fig. 2c, areas of cellular texture are observed starting from the melt 
boundaries. The etched cross-section of $\mathrm{T}_{\mathrm{H}, 4}$ in Fig. $2 \mathrm{~d}$ shows grey phases in the core area. The microstructure is characterized by a cellular structure.

With increasing preheating temperature up to $500{ }^{\circ} \mathrm{C}$, the microstructure becomes more fine-grained and homogeneous. At preheating temperature of $600{ }^{\circ} \mathrm{C}$ larger grains are present in the melt pool center. The microstructure in the area of the melt pool boundaries is characterized by smaller grains with predominantly cellular structure. The higher preheating temperatures in the core area favor grain growth and lead to larger grain structures.
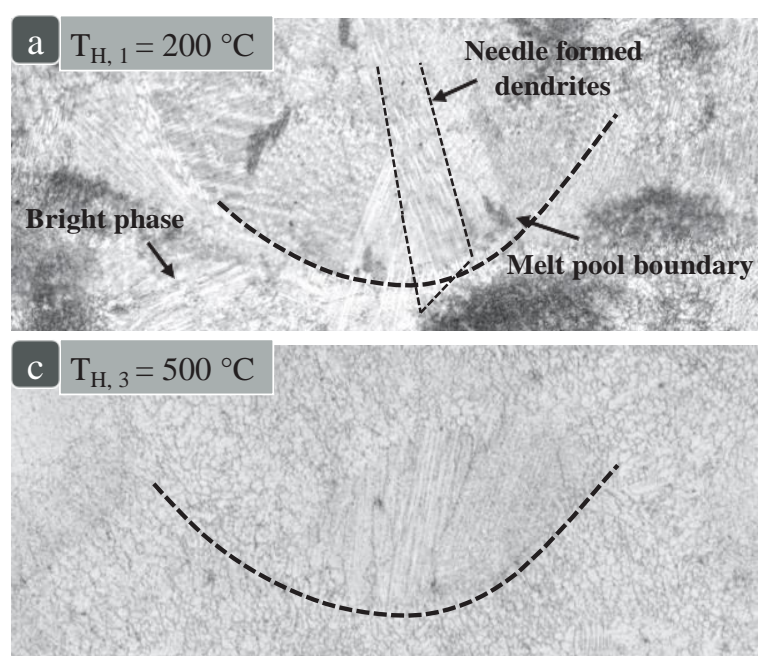

Fig. 2: LOM of etched cross-sections of specimen no. 2 built at preheating temperatures $\mathrm{T}_{\mathrm{H}, 1}(\mathrm{a})$, $\mathrm{T}_{\mathrm{H}, 2}(\mathrm{~b}), \mathrm{T}_{\mathrm{H}, 3}(\mathrm{c})$ and $\mathrm{T}_{\mathrm{H}, 4}(\mathrm{~d})$.

Fig. 3 shows the SEM images (BSE mode) of polished cross-sections of specimens no. 2 build at preheating temperatures $\mathrm{T}_{\mathrm{H}, 1}=200{ }^{\circ} \mathrm{C}$ and $\mathrm{T}_{\mathrm{H}, 4}=600{ }^{\circ} \mathrm{C}$. The matrix phase is bright while the cells are visibly dark. For $\mathrm{T}_{\mathrm{H}, 1}$ a dendritic structure is visible in Fig. 3a. Compared to $\mathrm{T}_{\mathrm{H}, 4}$, the matrix phase is very fine and the cells are smaller than $1 \mu \mathrm{m}$. The grain structure built at $\mathrm{T}_{\mathrm{H}, 4}$ is very homogeneously distributed and has a coarser structure (Fig. 3b). Due to the high preheating temperature $\mathrm{T}_{\mathrm{H}, 4}$ during the build job, grain growth is enabled which leads to larger grains compared to the microstructure of specimens build at lower preheating temperatures.


Fig. 3: SEM images (BSE mode) of polished cross-sections of specimen no. 2 built at preheating temperatures $\mathrm{T}_{\mathrm{H}, 1}(\mathrm{a})$ and $\mathrm{T}_{\mathrm{H}, 4}(\mathrm{~b})$.

The mean hardness of specimen built at $\mathrm{T}_{\mathrm{H}, 1}$ is $638 \pm 19 \mathrm{HV} 10$ and rises to $753 \pm 33$ HV10 with preheating temperature $\mathrm{T}_{\mathrm{H}, 2}$. The maximum mean hardness of specimen 
no. 2 is measured at $\mathrm{T}_{\mathrm{H}, 3}$ with $918 \pm 25 \mathrm{HV} 10$. With the highest preheating temperature $\mathrm{T}_{\mathrm{H}, 4}$ the hardness decreases to $729 \pm 32$ HV10.

But besides the mean hardness of the specimen it is necessary to analyze the part in different part heights because the used preheating system induced heat only into the base plate. Consequently, parts are subjected to temperature gradients and various heat treatment durations depending on preheating temperature and time during which the specimen is exposed to these temperatures during the LPBF process. Therefore, microstructure and mechanical properties of specimens in as-built condition vary depending on part height.

Fig. 4 shows the hardness over part height for specimen no. 2 built at preheating temperatures $\mathrm{T}_{\mathrm{H}, 1}-4$. The RA is determined by EBSD for different part heights of specimens built at preheating temperatures $\mathrm{T}_{\mathrm{H}, 1}, \mathrm{~T}_{\mathrm{H}, 3}$ and $\mathrm{T}_{\mathrm{H}, 4}$.

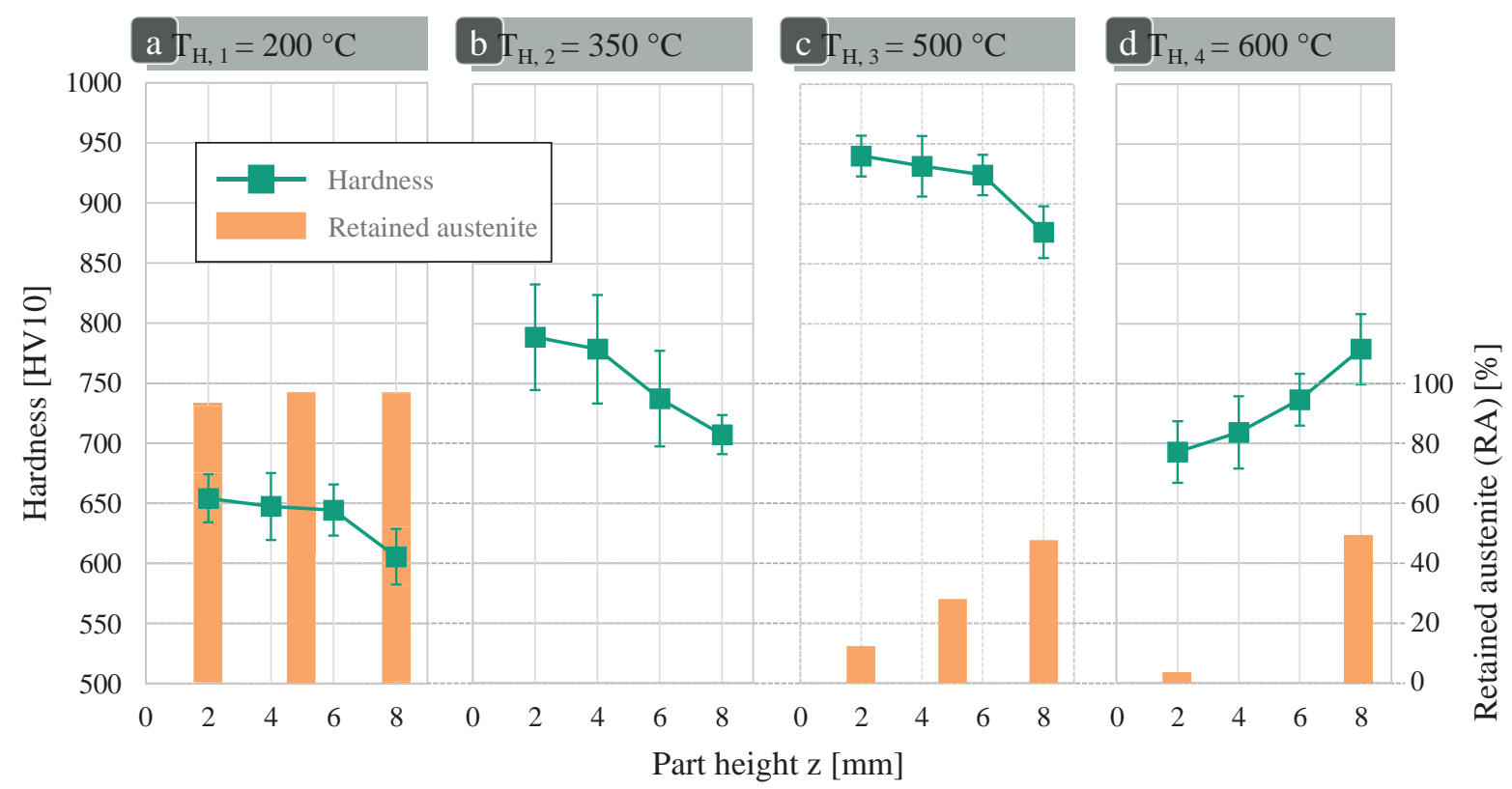

Fig. 4: Measured hardness and retained austenite (RA) over part height $\mathrm{z}$ for specimen no. 2 built at preheating temperature $\mathrm{T}_{\mathrm{H}, 1}(\mathrm{a}), \mathrm{T}_{\mathrm{H}, 2}(\mathrm{~b}), \mathrm{T}_{\mathrm{H}, 3}(\mathrm{c})$ and $\mathrm{T}_{\mathrm{H}, 4}(\mathrm{~d})$.

The hardness for specimens built at $\mathrm{T}_{\mathrm{H}, 1}$ is around $650 \mathrm{HV}$ for $\mathrm{z}=2-6 \mathrm{~mm}$. The hardness at $\mathrm{z}=8 \mathrm{~mm}$ decreases to $606 \pm 23600 \mathrm{HV}$. In contrast to the hardness, the RA at $\mathrm{z}=8 \mathrm{~mm}$ does not vary particularly compared to heights $\mathrm{z}=2-6 \mathrm{~mm}$. The RA is $93.9 \%$ in the lower part and rises to $96.7 \%$ in the upper part. For $\mathrm{T}_{\mathrm{H}, 2}$, only hardness measurements were performed. The hardness decreases over part height from $789 \pm 44 \mathrm{HV}$ at part height $\mathrm{z}=2 \mathrm{~mm}$ to $708 \pm 16 \mathrm{HV}$ at $\mathrm{z}=8 \mathrm{~mm}$. The hardness of the specimen built at $\mathrm{T}_{\mathrm{H}, 3}$ decreases as well from $940 \pm 17 \mathrm{HV}$ to $877 \pm 22 \mathrm{HV}$. The RA increases from $15.0 \%$ in the lower half to $47.3 \%$ in the upper part. In contrast to the other specimens, the hardness of specimen built at $\mathrm{T}_{\mathrm{H}, 4}$ increases over part height. The hardness is overall lower than of specimen built at $\mathrm{T}_{\mathrm{H}, 3}$ and rises from $693 \pm 26 \mathrm{HV}$ at $\mathrm{z}=2 \mathrm{~mm}$ to $779 \pm 29 \mathrm{HV}$ at $\mathrm{z}=8 \mathrm{~mm}$. The RA is very low in the lower half with $6.8 \%$ and increases to $65.2 \%$ in the upper half.

By infrared thermography (camera system: Optris PI640, Optris GmbH, Germany), the surface temperature of the specimens during the LPBF process could be monitored for all preheating temperatures. The temperature of the part surface increases by ascending part height at $\mathrm{T}_{\mathrm{H}, 1}$ of approx. $40-70{ }^{\circ} \mathrm{C}$. For $\mathrm{T}_{\mathrm{H}, 2}$ the measured temperature is constant for all part heights. Only for $\mathrm{T}_{\mathrm{H}, 3}$ and $\mathrm{T}_{\mathrm{H}, 4}$ the temperatures on the top surface of the specimens decrease over the part height. The difference over part height within $\mathrm{T}_{\mathrm{H}, 4}$ is higher and approx. $50{ }^{\circ} \mathrm{C}$. Together with the preheating system, the energy input of the laser beam in each layer helps to obtain the 
temperature in the specimen over part height. However, the first layers melted and solidified will be exposed to the preheating temperature for a longer time than the last layers of the part. Between the first and last layer of the part lie 210 minutes. The influence of this in-situ heat treatment on the microstructure and mechanical properties of the specimen can be noticed in the cross-sections at different build heights.

The mean hardness of specimens depends significantly on the preheating temperature. By increasing temperatures, the hardness is increasing and reaches its maximum at $\mathrm{T}_{\mathrm{H}, 3}$, while with even higher preheating temperature of $\mathrm{T}_{\mathrm{H}, 4}$ the hardness decreases again. This behavior can be compared to the conventional tempering diagram of HS6-5-3-8 [14]. A secondary hardness maximum is conventionally reached with tempering temperatures between 500 and $550{ }^{\circ} \mathrm{C}$. The hardness of high-speed steel is affected by martensite, which softens at increasing temperatures, the RA which transforms into martensite at higher temperatures and the precipitation of carbide phases due to high temperature.

Depending on the preheating temperature, opposite courses of hardness within the specimen height are determined. In the lower part, the longer heat treatment at $\mathrm{T}_{\mathrm{H}, 4}$ leads to a decrease in hardness. Again, this can be derived from the tempering diagram of HS6-5-3-8. When tempering for $2 \mathrm{~h}$ at $600{ }^{\circ} \mathrm{C}$, a decrease in hardness is observed. In the LPBF specimen, the RA is formed into martensite at this temperature. But the temperature above the hardness maximum and the duration of this in-situ heat treatment in the lower part softens all martensite. This leads to lower hardness even with higher carbide fractions. Therefore lower parts of the specimen could exceed the critical tempering time which leads to a decrease in hardness.

In Fig. 5 the phase map showing the distribution of fcc and bcc structured phases and the corresponding inverse pole figure (IPF) respectively of a single melt pool of specimen no. 2 built at preheating temperature $\mathrm{T}_{\mathrm{H}, 3}=500{ }^{\circ} \mathrm{C}$ is shown. The image is taken in the upper half of the specimen. The microstructure is characterized by large fractions of fcc (red) and bcc (blue) structured areas with sparsely distributed carbides (green) at the fcc-bcc boundaries.

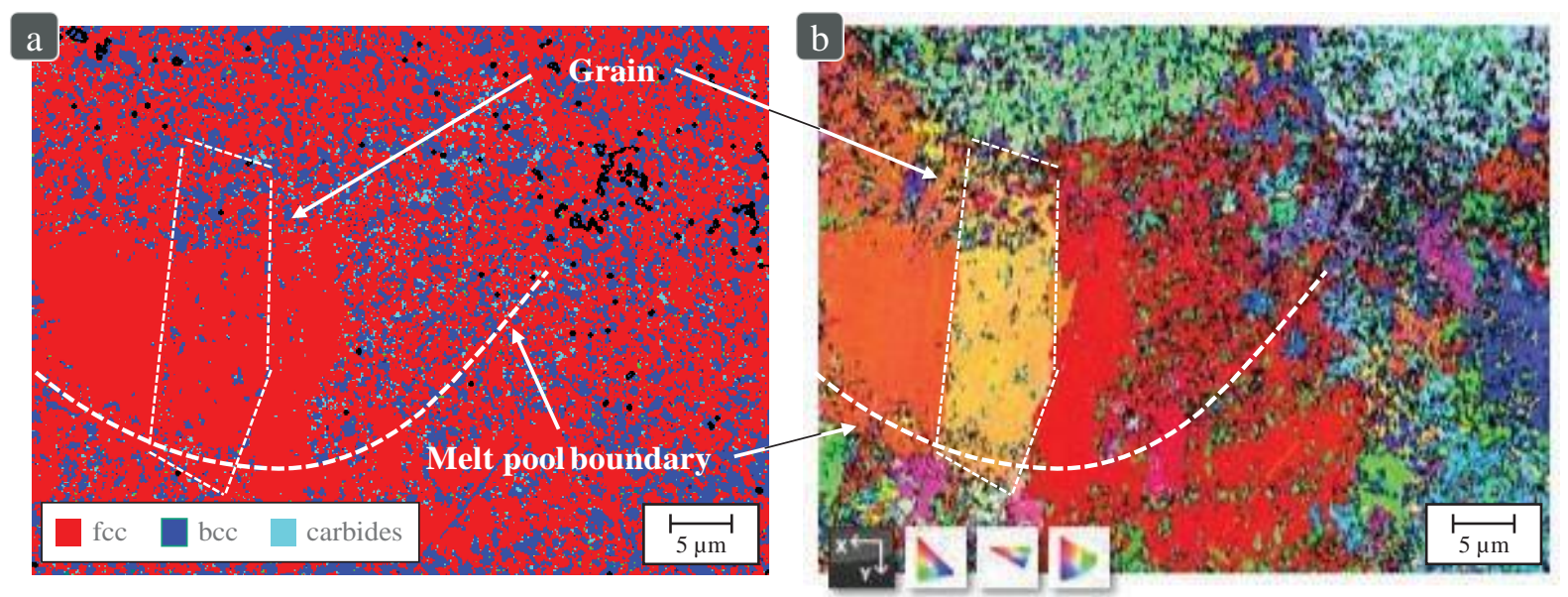

Fig. 5: Phase map, bcc (blue), fcc (red), carbides (green) (a) and IPF figure (b) of specimen no. 2 at preheating temperature $\mathrm{T}_{\mathrm{H}, 3}=500^{\circ} \mathrm{C}$.

Considering the chemical composition of the investigated steel the fcc-structured areas can be classified as RA occasionally enriched inside the melt pools, where comparably large grains are formed. Melt pool boundaries consist of a fine-grained duplex-like microstructure composed of bcc and fcc. However the IPF reveals the presence of areas with pronounced texture in bimodal structured regions. We hypothesize that the regions with pronounced texture are related to prior austenite grain boundaries, partially transforming to martensite during the cooling stage. In accordance with literature [15] high amounts of molybdenum carbides $\left(\mathrm{Mo}_{2} \mathrm{C}\right)$ are found. 


\section{Conclusion}

In this study, the material HS6-5-3-8 was processed at different preheating temperatures up to $600{ }^{\circ} \mathrm{C}\left(\mathrm{T}_{\mathrm{H}, 1}=200{ }^{\circ} \mathrm{C}, \mathrm{T}_{\mathrm{H}, 2}=350{ }^{\circ} \mathrm{C}, \mathrm{T}_{\mathrm{H}, 3}=500{ }^{\circ} \mathrm{C}\right.$ and $\left.\mathrm{T}_{\mathrm{H}, 4}=600{ }^{\circ} \mathrm{C}\right)$. The investigated specimens at each preheating temperature have a part density above $99.9 \%$. We demonstrate the influence of preheating temperature on the processability of HS6-5-3-8 and give first insights into how the LPBF process influences microstructure and hardness of the material.

The preheating temperature influences macro cracks, hardness and microstructure of the specimens. Different crack types were observed depending on preheating temperature. At $\mathrm{T}_{\mathrm{H}, 2}$ fewer to no cracks were detected compared to other preheating temperatures investigated. In the specimens built with the highest preheating temperature the most amounts of cracks were observed. The mean hardness increases with increasing preheating temperature and reaches a maximum at $\mathrm{T}_{\mathrm{H}, 3}$ with $940 \mathrm{HV} 10$. Using $\mathrm{T}_{\mathrm{H}, 4}$ again lower hardness levels are reached. The microstructure at lower preheating temperature shows more needle-formed dendrites while at higher preheating temperature the microstructure gradually transforms into larger cellular grains.

The hardness is not constant over part height. Depending on preheating temperature the hardness can increase with $\mathrm{T}_{\mathrm{H}, 1-3}$ or decrease with $\mathrm{T}_{\mathrm{H}, 4}$ over part height. This behavior is explained by in-situ heat treatment processes, were the lower parts of specimens are exposed to the preheating temperature for a longer time period than the upper parts. Similar to the conventional tempering diagram, where the secondary hardness maximum is located at 500 to $550{ }^{\circ} \mathrm{C}$, the hardness of lower part built at $\mathrm{T}_{\mathrm{H}, 3}$ is maximum.

\section{Acknowledgement}

This project was carried out with the support of the European Regional Development Fund ERDF under grant number EFRE-800665.

\section{References}

[1] GEBHARDT, A.: Understanding additive manufacturing: Rapid prototyping, rapid tooling, rapid manufacturing. Hanser, Munich, 2012

[2] Gibson, I., Rosen, D. W., and Stucker, B., Additive Manufacturing Technologies: 3D Printing, Rapid Prototyping, and Direct Digital manufacturing, 2nd ed., Springer, New York, 2015, pp. 1-498.

[3] MEINERS, W.: Direktes selektives Laser Sintern einkomponentiger metallischer Werkstoffe. Dissertation. Aachen 1999

[4] LIU, Z. H.; Liu, Z.; Chua, C.; Leong, K.; Kempen, K.; Thijs, L.; Yasa, E.; VanHumbeeck, J.; Kruth, J.: A preliminary investigation on Selective Laser Melting of M2 high speed steel. In: Soares de Lemos, Ana Cristina (ed.): Innovative developments in virtual and physical prototyping: Proceedings of the 5th International Conference on Advanced Research and Rapid Prototyping, Leiria, Portugal, 2011

[5] LIU, Z. H.; Zhang, D. Q.; Chua, C. K.; Leong, K. F.: Crystal structure analysis of M2 high speed steel parts produced by selective laser melting. In: Materials Characterization Vol. 84, 2013 
[6] KEMPEN, K.; Vrancken, B.; Buls, S.; Thijs, L.; van Humbeeck, J.; Kruth, J.-P.: Selective Laser Melting of Crack-Free High Density M2 High Speed Steel Parts by Baseplate Preheating. In: Journal of Manufacturing Science and Engineering 136, No. 6, 2014

[7] ZUMOFEN, L.; Beck, C.; Kirchheim, A.; Dennig, H.-J.: Quality Related Effects of the Preheating Temperature on Laser Melted High Carbon Content Steels. In: Klahn, Christoph (ed.): Industrializing Additive Manufacturing - Proceedings of Additive Manufacturing in Products and Applications - AMPA2017: Springer International Publishing. Cham, 2018

[8] FEUERHAHN, F.; Schulz, A.; Seefeld, T.; Vollertsen, F.: Microstructure and Prop-erties of Selective Laser Melted High Hardness Tool Steel. In: Physics Procedia Vol: 41, 2013

[9] SANDER, J.: Selektives Laserschmelzen hochfester Staehle. Dresden, TU Dresden, Fakultaet fuer Maschinenwesen. Dissertation, 2018

[10] KUNZ, J.; Herzog, S.; Kaletsch, A.; Broeckmann, C.; Saewe, J.; Gayer, C.; Schleifenbaum, J. H.: Influence of Powder Bed Temperature on Microstructure and Post Heat Treatment of High Speed Steel AISI M50 Processed by Laser Powder Bed Fusion. In: International Powder Metallurgy Congress and Exhibition, Euro PM2018 Proceedings, Bilbao, 2018

[11] SAEWE, J.; Gayer, C.; Vogelpoth, A.; Schleifenbaum, J. H.: Feasability Investigation for Laser Powder Bed Fusion of High-Speed Steel AISI M50 with Base Preheating System. In: BHM Berg- und Huettenmaennische Monatshefte Vol. 164, 2019

[12] KUNZ, J.; Herzog, S.; Kaletsch, A.; Saewe, J.; Schleifenbaum, J. H.; Broeckmann, C.: Mechanical Properties of High Speed Steel AISI M50 Produced by Laser Powder Bed Fusion. In: Tooling2019, Aachen, 2019

[13] SAEWE, J.; Gayer, C.; Jauer, L.; Kunz, J.; Broeckmann, C.; Schleifenbaum, J. H.: Feasibility Investigation for Laser Powder Bed Fusion of High-Speed Steels. In: International Powder Metallurgy Congress and Exhibition, Euro PM2018 Proceedings, Bilbao, 2018

[14] ASP@2030 Powder metallurgy HSS. ASP® Steels, ERASTEEL 2018, www.erasteel.com/content/asp-steels-0

[15] ZHAO, S.-L.; Fan, J.-F.; Zhang, J.-Y.; Shou K.-C.; Le, H.-R.: High speed steel produced by spray forming. In: Advanced Manufacturing Vol. 4, 2016 